\title{
Inclination and Alsberg angle changes in hip degenerative arthritis
}

\author{
Yasin Emre Kaya, ${ }^{1}{ }^{\text {D }}$ Seda Sertel Meyvaci ${ }^{2}$ \\ ${ }^{1}$ Department of Orthopedics and Traumatology, Bolu Abant Izzet Baysal University, Faculty of Medicine, Bolu, Turkey \\ ${ }^{2}$ Department of Anatomy, Bolu Abant Izzet Baysal University, Faculty of Medicine, Bolu, Turkey
}

\begin{abstract}
Aim: To compare the inclination and Alsberg angles of both hips in patients with unilateral coxarthrosis and healthy population.
\end{abstract}

Methods: 89 patients who underwent total hip replacement due to end-stage unilateral idiopathic coxarthrosis between 2016 and 2019 in Bolu Abant Izzet Baysal University Orthopedics and Traumatology Department and had preoperative pelvic anteroposterior radiographs were included in the study. A total of 87 patients with pelvic radiographs taken due to low back pain or minor trauma were included in the study as control group. Patients with bilateral end-stage coxarthrosis, any lower extremity fractures, secondary coxarthrosis caused by any reasons like Perthes disease, trauma, avascular necrosis, hematologic disease etc. and unsuitable radiographs were excluded from the study. Two researchers took the measurements separately and the averages were considered and the results were analyzed statistically.

Results: Statistically significant differences were detected between the right side and the left side in terms of both Alsberg and hip inclination values in individuals of healthy control group. In patients with unilateral osteoarthritis, no significant differences were detected between right and left sides in terms of hip inclination values. Similarly, no significant difference was found between the right and left sides in terms of Alsberg values in patients with unilateral osteoarthritis. The Alsberg angle was found to be higher at statistically significant levels in patients with unilateral hip osteoarthritis, in both the osteoarthritis side and the contralateral hip, compared to the values in healthy individuals.

Conclusion: When compared with healthy individuals, it was concluded that the Alsberg and inclination angles changed with the development of unilateral coxarthrosis. While significant differences were detected between the sides for Alsberg and inclination angle in healthy individuals, this difference between the sides was not observed in the coxarthrosis groups. With the development of unilateral coxarthrosis, it was concluded that the asymmetry between the right and left sides of healthy individuals disappeared and a more symmetrical structure emerged in terms of Alsberg and hip inclination angles.

Keywords: Hip inclination angle, neck - shaft angle, Alsberg angle, osteoarthritis.

\section{$\triangle D r$. Yasin Emre Kaya}

Department of Orthopaedics and Traumatology,

Bolu Abant Izzet Basal University Faculty of Medicine,

Bolu, Turkey

E-mail: yemrek@hotmail.com

Received: 2021-01-22 Revised: 2021-01-30

Accepted: 2021-02-08

Published online: 2021-04-01

\section{Introduction}

Osteoarthritis is a chronic degenerative disease of snovial joints [1] and characterized by deteroriation of the articular cartilage, formation of subchondral sclerosis, osteophytes and subchondral cysts in the adjacent bones of joint. Also biochemical and morphological changes are seen in the synovial membrane and 
joint capsule [2,3]. It is the most common disease of joints and its frequency increases with age [4,5]. There are many factors responsible in the etiology of osteoarthritis. Especially in hip osteoarthritis, genetic, biomechanical and metabolic factors contribute the destruction of cartilage. Secondary coxarthrosis causes such as trauma, perthes disease, rheumatoid arthritis are common as idiopathic causes [6].

Plain radiographs of the hip are inexpensive, widely available and readily available. Therefore, evaluation of osteoarthritis is not as difficult as other imaging modalities. Anteroposterior (AP) and lateral radiographs of the hip are obtained to examine hip osteoarthritis. As the disease progresses, the joint space narrows and radiological changes occur $[7,8]$. In the last stage, the anatomy of the femoral head and acetabulum changes. This causes other problems in adjacent joints and spine. The inclination angle (IA) and Alsberg angle (AA) is a decisive factor in determining the strength and stability of the femur [9]. Therefore, we think that degenerative changes in the hip will cause changes in both angles, which will lead to pathologies in neighboring joints.

The purpose of the present study was to compare the IA and AA of both hips in patients who had unilateral coxarthrosis and healthy population.

\section{Materials and Methods}

After getting the approval from the Ethics committee of Bolu Abant Izzet Baysal University (2020/79), 89 patients who underwent total hip replacement due to endstage unilateral idiopathic coxarthrosis between 2016 and 2019 in Bolu Abant Izzet Baysal University Orthopedics and Traumatology Department and had preoperative pelvic AP radiographs were included in the study. A total of 87 patients with pelvic radiographs taken due to low back pain or minor trauma were included as the control group in the study. Patients who had bilateral end-stage coxarthrosis, any lower extremity fractures, secondary coxarthrosis caused by any reasons like Perthes disease, trauma, avascular necrosis, hematologic disease etc. and unsuitable radiographs were excluded.

Age and gender distributions of the participants were evaluated. Two researchers took the measurements separately and the averages were considered and the results were analyzed statistically.

\section{Radiological evaluation}

The IA of hip was calculated by measuring the angle between the line parallel to the femoral head-neck and the line parallel to the femur shaft on pelvic AP radiographs (Figure 1A). The AA was calculated by measuring the the angle between the axis of the femur shaft and the base of epiphyseal plate of femoral head (Figure 1B) [9].

\section{Statistical Analysis}

Numerical variables were described with arithmetic mean and standard deviation or median and minimum-maximum values and count (percentage) values were used to summarize categorical variables. Normality of data was assessed using both graphical (histogram, Q-Q plot, etc.) and analytical (Kolmogorov - Smirnov test) approaches. Comparison of numerical variables between groups were made with Student's t test or Mann-Whitney $U$ test for two independent groups, and one-way ANOVA and KruskalWallis test for three or more independent groups according to normality of data. Finally, a post-hoc test was performed to explore 
pairwise differences. Dependent groups were compared with paired t-test or Wilcoxon paired test. Statistical Analyses were made with IBM SPSS v.21. Statistical significance was taken as $p<0.05$.
The mean IA value of the left coxarthrosis group is $132.08^{\circ}$ for right side and $135.25^{\circ}$ for left side. No significant differences were detected between left and right sides for mean IA values of left coxarthrosis group $(p=0.052)$.
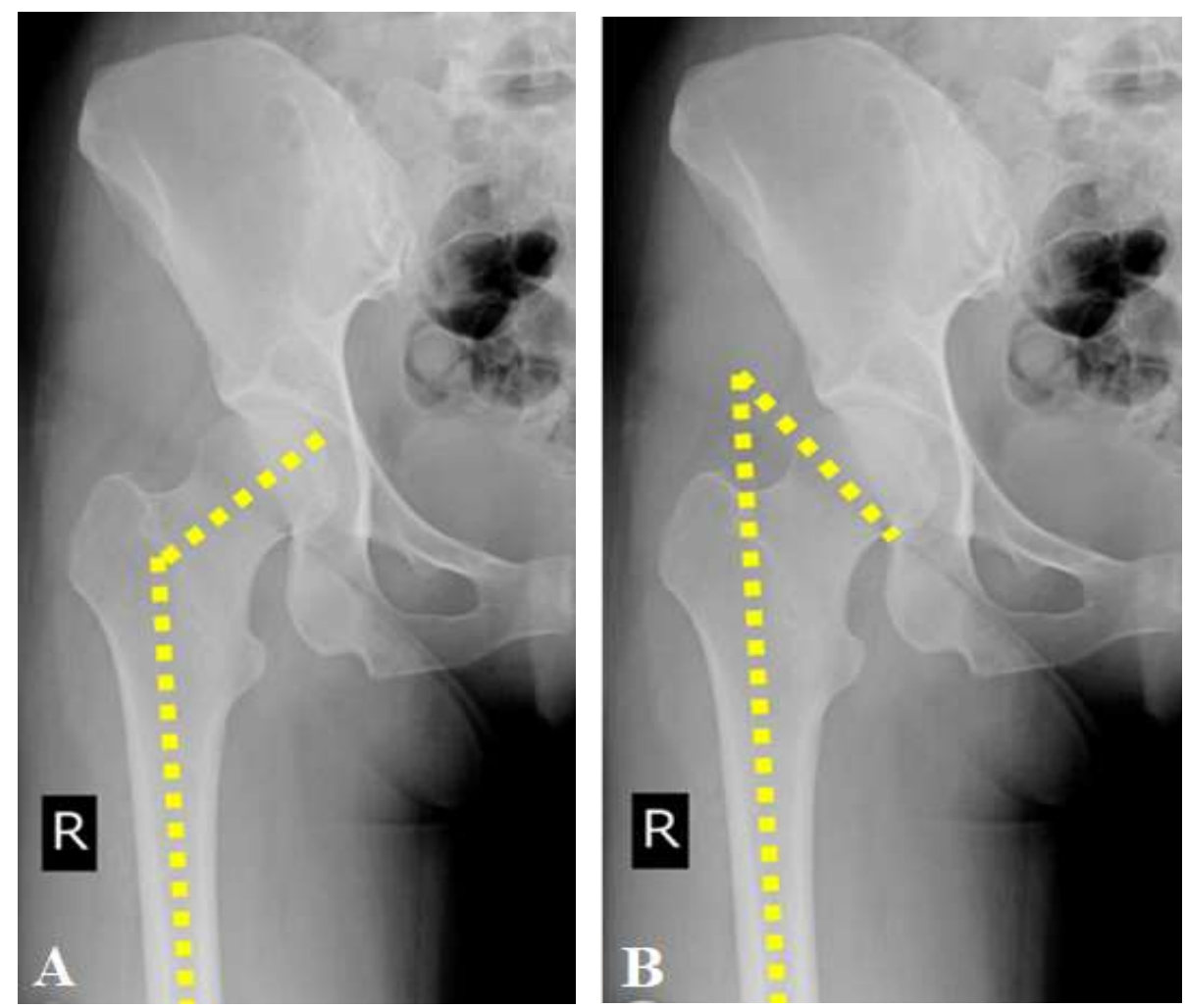

Figure 1. A) Inclination angle, the angle between the yellow line parallel to the femoral head-neck and the yellow line parallel to the femur shaft. B) The Alsberg angle was calculated by measuring the the angle between the axis of the femur shaft and the base of epiphyseal plate of femoral head.

\section{Results}

A total of 176 patients who had a mean age of 69 (ranging from 60 to 81; Standart Deviation: $5.22)$ were reached. $89(50.6 \%)$ of the patients were females and $87(49.4 \%)$ were males (Table 1).

The mean IA value of the control group is $134.1^{\circ}$ for right side and $130.7^{\circ}$ for left side. Right IA values of the control group were higher at statistical levels $(p=0.007)$. The mean AA value of the control group was $39.5^{\circ}$ for right side and $41.9^{\circ}$ for left side. Left AA values of the control group were higher at statistical levels $(p=0.022)$ (Table 2).
Table 1. Group, gender and age distribution of 176 patients.

\begin{tabular}{|l|c|}
\hline Variables & N (\%) \\
\hline Groups & $44(25.0 \%)$ \\
Left coxartrosis & $45(25.6 \%)$ \\
Right coxartrosis & $87(49.4 \%)$ \\
Control & $89(50.6 \%)$ \\
\hline Gender & $87(49.4 \%)$ \\
Female & \\
Male & $69.0 \pm 5.22(60-81)$ \\
\hline Age (year) & \\
\hline
\end{tabular}


The mean AA value of left coxarthrosis group is $44.97^{\circ}$ for right side and 48.35 for left side. Left AA values of left coxarthrosis group were higher at statistical levels $(p=0.024)$ (Table 2). The mean IA value of the group with right coxarthrosis is $130.2^{\circ}$ for right side and $128.7^{\circ}$ for left side. The mean IA values of the right coxarthrosis group were not significantly different between the right and left sides $(\mathrm{p}=0.804)$. The average AA value of the group with right coxarthrosis is $50.9^{\circ}$ for the right side and $49.6^{\circ}$ for the left side. No significant differences were detected between right and left sides for mean AA values of right coxarthrosis group ( $p=0.915$ ) (Table 2).

Significant differences were detected between right coxarthrosis group and control group in terms of mean right IA values $(p=0.004)$. Significant differences were also detected between left coxarthrosis group and control group for mean left IA values $(p<0.001)$ (Table 2).

Significant differences were detected between control group and other groups in terms of mean right AA values. Mean right AA of control group was lower than right and left coxarthrosis groups $(p=0.043)$. And significant differences were also detected between control group and other groups for mean left AA values. Mean left AA of control group was lower than right and left coxarthrosis groups $(p<0.001)$ (Table 2$)$.

No significant differences were detected between operated side and healthy side for IA values $(p=0.238)$. No significant differences were detected between operated side and healthy side for AA values $(p=0.090)$ (Table $3)$.

Table 2. Comparison of the angle measurements by the groups and sides.

\begin{tabular}{|c|c|c|c|c|c|c|}
\hline \multirow[b]{2}{*}{ Variables } & \multicolumn{2}{|c|}{$\begin{array}{c}\text { Inclination angle } \\
\text { Median (min.-max.) }\end{array}$} & \multirow[b]{2}{*}{$p$} & \multicolumn{2}{|c|}{$\begin{array}{c}\text { Alsberg angle } \\
\text { Median (min.-max.) }\end{array}$} & \multirow[b]{2}{*}{$p$} \\
\hline & Right & Left & & Right & Left & \\
\hline $\begin{array}{l}\text { Left } \\
\text { Coxarthrosis }\end{array}$ & $\begin{array}{l}132.08^{\mathrm{a}, \mathrm{b}} \\
(119.5-148.9)\end{array}$ & $\begin{array}{l}135.25^{\mathrm{a}} \\
(77-159.9)\end{array}$ & 0.052 & $\begin{array}{l}44.97^{\mathrm{a}} \\
(31.2-57.1)\end{array}$ & $\begin{array}{l}48.35^{\mathrm{a}} \\
(13.63-67.3)\end{array}$ & 0.024 \\
\hline $\begin{array}{l}\text { Right } \\
\text { Coxarthrosis }\end{array}$ & $\begin{array}{l}130.2^{\mathrm{a}} \\
(112.3-145.1)\end{array}$ & $\begin{array}{l}128.7^{\mathrm{b}} \\
(87.2-159)\end{array}$ & 0.804 & $\begin{array}{l}50.9^{\mathrm{a}} \\
(36-64)\end{array}$ & $\begin{array}{l}49.6^{\mathrm{a}} \\
(25.8-64.7)\end{array}$ & 0.915 \\
\hline Control & $\begin{array}{l}134.1^{\mathrm{b}} \\
(115.4-154.1)\end{array}$ & $\begin{array}{l}130.7^{\mathrm{a}, \mathrm{b}} \\
(109.6-162.4)\end{array}$ & 0.007 & $\begin{array}{l}39.5^{\mathrm{b}} \\
(26-58.2)\end{array}$ & $\begin{array}{l}41.9^{\mathrm{b}} \\
(22.8-55.0)\end{array}$ & 0.022 \\
\hline$p$ & 0.004 & $<0.001$ & & 0.043 & $<0.001$ & \\
\hline
\end{tabular}

According to the post hoc test results, the different groups are shown with different letters $(a, b)$, non-different groups are shown with the same letters ( $a$ or $b$ ).

Table 3. Comparison of the angle values according to the operation status.

\begin{tabular}{|l|c|c|c|c|}
\hline Variables & $\begin{array}{c}\text { Inclination angle } \\
\text { Median (min.-max.) }\end{array}$ & $\boldsymbol{p}$ & $\begin{array}{c}\text { Alsberg angle } \\
\text { Median (min.-max.) }\end{array}$ & $\boldsymbol{p}$ \\
\hline Operated side & $131.1(77-159.9)$ & \multirow{2}{*}{0.238} & $49.3(13.63-67.3)$ & \multirow{2}{*}{0.090} \\
\cline { 1 - 2 } Healthy side & $130.4(87.2-159)$ & & $46.2(25.8-65.7)$ & \\
\hline
\end{tabular}


In females, no significant differences were detected in IA values between operated side and healthy side $(p=0.446)$. No significant differences were detected in females between operated side and healthy side regarding AA values $(p=0.102)$ (Table 4).
No significant differences were detected in IA values between operated side and healthy side in males $(p=0.394)$. No significant differences were detected in males between operated side and healthy side regarding AA values $(p=0.473)($ Table 4).

Table 4. Comparison of the angle values according to the operation status in terms of gender.

\begin{tabular}{|c|c|c|c|c|c|c|}
\hline \multirow{2}{*}{ Gender } & \multicolumn{2}{|c|}{$\begin{array}{c}\text { Inclination angle } \\
\text { Median (min.-max.) }\end{array}$} & $\boldsymbol{p}$ & \multicolumn{2}{|c|}{$\begin{array}{c}\text { Alsberg angle } \\
\text { Median (min.-max.) }\end{array}$} & $\boldsymbol{p}$ \\
\cline { 2 - 7 } & Operated & Healthy & & Operated & Healthy & \\
\hline \multirow{2}{*}{ Female } & $\begin{array}{c}130.2 \\
(112.3-159.9)\end{array}$ & $\begin{array}{c}129.9 \\
(87.2-150.7)\end{array}$ & 0.446 & $\begin{array}{c}49.7 \\
(32.3-67.3)\end{array}$ & $\begin{array}{c}45.5 \\
(25.8-65.0)\end{array}$ & 0.102 \\
\hline \multirow{2}{*}{ Male } & $\begin{array}{c}131.79 \\
(77-157.14)\end{array}$ & $\begin{array}{c}133.05 \\
(96.2-159)\end{array}$ & 0.394 & $\begin{array}{c}49.1 \\
(13.63-64.0)\end{array}$ & $\begin{array}{c}46.65 \\
(31.2-65.7)\end{array}$ & 0.473 \\
\hline
\end{tabular}

Table 5. Comparison of the angle measurements according to gender in terms of the patient groups.

\begin{tabular}{|c|c|c|c|c|c|c|}
\hline \multirow{2}{*}{ Variables } & \multicolumn{2}{|c|}{$\begin{array}{c}\text { Inclination angle } \\
\text { Mean } \pm \text { SD }\end{array}$} & \multirow[t]{2}{*}{$p$} & \multicolumn{2}{|c|}{$\begin{array}{c}\text { Alsberg angle } \\
\text { Mean } \pm \text { SD }\end{array}$} & \multirow[t]{2}{*}{$p$} \\
\hline & Right & Left & & Right & Left & \\
\hline \multicolumn{6}{|l|}{ Female } & \\
\hline $\begin{array}{l}\text { Left } \\
\text { Coxarthrosis }\end{array}$ & $131.43 \pm 7.47$ & $136.06^{\mathrm{a}} \pm 10.57$ & 0.055 & $45.86^{\mathrm{a}} \pm 5.94$ & $50.68^{a} \pm 9.26$ & 0.006 \\
\hline $\begin{array}{l}\text { Right } \\
\text { Coxarthrosis }\end{array}$ & $127.79 \pm 8.32$ & $128.32^{\mathrm{b}} \pm 12.19$ & 0.879 & $47.52^{\mathrm{a}} \pm 6.42$ & $47.90^{a} \pm 10.06$ & 0.868 \\
\hline Control & $131.86 \pm 6.33$ & $129.04^{\mathrm{b}} \pm 7.44$ & 0.034 & $39.94^{\mathrm{b}} \pm 5.19$ & $40.76^{\mathrm{b}} \pm 5.20$ & 0.354 \\
\hline$p$ & 0.082 & 0.011 & & $<0.001$ & $<0.001$ & \\
\hline \multicolumn{7}{|l|}{ Male } \\
\hline $\begin{array}{l}\text { Left } \\
\text { Coxarthrosis }\end{array}$ & $132.73^{\mathrm{a}, \mathrm{b}} \pm 7.09$ & $131.74 \pm 18.75$ & 0.820 & $44.2^{\mathrm{a}} \pm 7.31$ & $42.99^{\mathrm{a}} \pm 12.62$ & 0.707 \\
\hline $\begin{array}{l}\text { Right } \\
\text { Coxarthrosis }\end{array}$ & $130.9^{\mathrm{a}} \pm 6.32$ & $130.57 \pm 14.64$ & 0.915 & $50.73^{\mathrm{b}} \pm 6.92$ & $50.15^{b} \pm 9.43$ & 0.731 \\
\hline Control & $136.71^{\mathrm{b}} \pm 7.80$ & $135.20 \pm 8.64$ & 0.178 & $40.45^{\mathrm{a}} \pm 6.38$ & $42.61^{\mathrm{a}} \pm 6.03$ & 0.020 \\
\hline$p$ & 0.009 & 0.358 & & $<0.001$ & 0.005 & \\
\hline
\end{tabular}

According to the post hoc test results, the different groups are shown with different letters $(a, b)$, non-different groups are shown with the same letters ( $a$ or $b$ ). 
In females, statistically significant differences were detected between right and left sides according to IA values of the control group ( $p=0.034)$. Right IA values of the control group are higher. In females, no statistically significant differences were detected between the right and left sides of the control group according to the AA values $(p=0.354)$ (Table $5)$. In females, no statistically significant differences were detected between right and left sides of the left coxarthrosis group according to the IA values $(p=0.055)$. Statistically significant differences were detected between left and right sides of left coxarthrosis group in females according to the AA values $(p=0.006)$. The healthy side values are lower (Table 5).

In females, no statistically significant differences were detected between right and left sides according to IA values of right coxarthrosis group $(p=0.879)$. In females, no statistically significant differences were detected between right and left sides of right coxarthrosis group according to the AA values $(p=0.868)$ (Table 5). In males, no statistically significant differences were detected between right and left sides of left coxarthrosis group according to the IA values $(p=0.820)$. There were no statistically significant differences between left and right sides of left coxarthrosis group in males according to the AA values $(p=0.707)$ (Table 5).In men, there were no statistically significant differences between right and left sides of right coxarthrosis group according to the IA values $(p=0.915)$. There were no statistically significant differences between right and left sides of right coxarthrosis group in males according to the AA values $(p=0.731)$ (Table 5).

\section{Discussion}

When the literature is reviewed, it is seen that hip IA and AA values differ according to age, gender and races. In this study the distribution of hip IA and AA in the elder and healthy population was determined since patients without complaints in the hip joint were selected as the control group. In the control group, the mean value of IA was higher in the right hip, while the mean value of the AA was higher in the left hip. In an anatomy study on a younger population (aged 30 to 40) by Oguz et al, [9] the mean IA was measured as $123.7^{\circ}$ and $125.9^{\circ}$ in the measurements made on 25 right and 25 left femurs, respectively. In the same study, right and left average AA were measured as $39.92^{\circ}$ and $40.61^{\circ}$, respectively. There were no statistically significant differences for IA and AA for right and left femur [9]. In our study, when right and left side values of control group were compared, there was an asymmetric condition in terms of both IA and AA. This study with more patients will provide the literature on the values in the elder and healthy population as well. R Sherestha et al., in their study on Nepalese people, classified 148 healthy individuals according to age (21-40, 4160 and over 60 years) and gender (male female) and measured the right and left hip IA. They reported the mean of right and left hip IA values as $132.47^{\circ}$ and $128.84^{\circ}$, respectively, in individuals over 60 years of age, they reported that the mean IA of the right hip was higher than the left, but there were statistically significant differences [10]. Similarly, in our study, the mean right hip IA value was higher in the control group compared to the left side, but this height was found to be significant on the right side in our study. In the same study, they determined the mean right and left hip IA as $134^{\circ}$ and $132.98^{\circ}$, respectively, and they revealed that there were statistically significant differences. They found the mean right and left hip IA in males as $132.96^{\circ}$ and $131.54^{\circ}$, respectively, and reported no significant 
differences between the two sides. Likewise, in our study, the mean right and left IA values in the measurements performed in females in the control group were found to be $131.86^{\circ}$ and $129.04^{\circ}$, respectively, and the right side value was found to be significantly higher than the left side. In the measurements performed in the males in the control group in our study, the mean right and left IA values were found to be $136.71^{\circ}$ and $135.20^{\circ}$, respectively, and no statistically significant differences were detected. Our study supports the literature in the light of these data. Tahir A et al., in their study on natives living in the north-east sub-region of Nigeria, reported the mean hip IA values of 200 males and 120 females as $136.7^{\circ}$ and $126.65^{\circ}$, respectively, and they reported that the average hip IA in males living in this region was statistically significantly higher than in females [11]. In our study, statistically significant differences were found between genders in terms of hip IA values. However, this value was higher for males on the right side, while it was higher for females on the left side. These similarities and differences seen in studies on hip IA reveal the importance and effect of age range, race and gender of the studied population on these values.

Another important finding is the angle changes in the degenerated hip and healthy hip when unilateral primary coxarthrosis develops. Laforgia $\mathrm{R}$ et al. evaluated radiographic variables on normal and osteoarthritic hips and reported that deterioration in hip IA and other variables correlated directly with the development of hip osteoarthritis [12]. Mills HJ et al. examined the relationship between proximal femoral anatomy and coxarthrosis and reported that the hip IA was significantly higher in hips with coxarthrosis [13]. Doherty $\mathrm{M}$ et al. stated that the nonspherical femoral head and high IA seen in pistol grip deformity may be the result of osteoarthritis [14]. In contrast to these studies, Reikeras and Hoiseth reported that there was no significant difference in hip IA between normal hips and hips with osteoarthritis when they compared hip IA of 44 patients with unilateral or bilateral hip idiopathic osteoarthritis with normal values [15]. Our study supports the articles reporting that hip IA have changed with the development of osteoarthritis. We demonstrated that the hip IA was changed as well as the AA. When we look at the mean angle values of right and left sides in control group in our study, we concluded that the IA values were significantly higher on right side, and AA values were higher at significant levels on left side. This situation reveals that there is an asymmetry between the sides in terms of hip IA and AA values in individuals over 60 years of age. With the development of osteoarthritis, we reached the result that this asymmetry disappeared in terms of both AA and IA values, and that the significant difference between the right and left hips disappeared with the development of osteoarthritis. When Labronici et al. compared the contralateral hip angles with osteoarthritis and healthy ones, they reported that there was no significant difference between hip IA [16]. In this study, our results overlap with this study. When we compared the mean IA value of the right hip of the coxarthrosis group and the mean right hip IA value of the control group, we concluded that the value of the control group was significantly higher. However, when we compared the mean left hip IA value of the coxarthrosis group with the left value of the control group, we concluded that the mean IA value of the coxarthrosis group was higher this time. Based on this, it is not possible to say that the IA value generally increases or decreases with the development of osteoarthritis, according to our results. The more striking 
result of our study is that, with the development of osteoarthritis, the IA and AA values approach each other with the opposite hip and these angles become more symmetrical. In addition, the AA contributes to the symmetry that occurs with the development of idiopathic osteoarthritis by increasing in both the osteoarthritis developing side and the contralateral hip.

\section{Conclusion}

In the present study, statistically significant differences were detected between right side and left side for both AA and hip IA values in individuals over 60 years of age with radiographically and clinically bilateral healthy hip joints. These angles change with the development of osteoarthritis. In patients with unilateral osteoarthritis, no significant differences were detected between right and left sides regarding hip IA values. Similarly, no significant differences were detected between the right and left sides regarding AA values in patients with unilateral osteoarthritis. It was concluded that the angular asymmetry observed in healthy individuals disappeared with the development of osteoarthritis, and the sides took on a more symmetrical structure. The AA was higher at statistically significant levels in patients with unilateral hip osteoarthritis, in both the osteoarthritis side and the contralateral hip, compared to the values in healthy individuals.

Funding: There is no financial support and sponsorship

Conflict of Interest: The authors declare that they have no conflict of interest.

Ethical statement: The study was approved by the Ethics committee of Bolu Abant Izzet Baysal University (Date and decision no: 2020/79).

\section{Open Access Statement}

This is an open access journal which means that all content is freely available without charge to the user or his/her institution under the terms of the Creative Commons Attribution NonCommercial License (http://creativecommons.org/licenses/bync/4.0). Users are allowed to read, download, copy, distribute, print, search, or link to the full texts of the articles, without asking prior permission from the publisher or the author.

\section{References}

[1]Mobasheri A, Batt M. An update on the pathophysiology of osteoarthritis. Ann Phys Rehabil Med. 2016; 59(5-6):333-39.

[2]Ayanoglu T, Atalar H, Esen E, et al. The role of ADAMTS genes in the end stage of hip osteoarthritis. Acta Orthop Traumatol Turc. 2019; 53(2):140-44.

[3]Griffin TM, Scanzello CR. Innate inflammation and synovial macrophages in osteoarthritis pathophysiology. Clin Exp Rheumatol. 2019; 37(5):57-63.

[4]Loeser RF. Age-related changes in the musculoskeletal system and the development of osteoarthritis. Clin Geriatr Med. 2010; 26(3):371-86.

[5]Goldring SR, Goldring MB. Clinical aspects, pathology and pathophysiology of osteoarthritis. J Musculoskelet Neuronal Interact. 2006; 6(4):376-78.

[6]Macovei L, Brujbu I, Murariu RV. Coxarthrosis--disease of multifactorial etiology methods of prevention and treatment. The role of kinesitherapy in coxarthrosis. Rev Med Chir Soc Med Nat Iasi. 2013; 117(2):351-57.

[7]Schueller G, Schueller-Weidekamm C. Koxarthrose - eine radiologische Annäherung und Leitfaden [Coxarthrosis - a 
radiological approach and guidelines]. Der

Radiologe. 2012; 52(2):156-62.

[8]Kellgren JH, Lawrence JS. Radiological assessment of osteo-arthrosis. Ann Rheum Dis. 1957; 16(4):494-502.

[9]Oguz Ö. Measurement and relationship of the inclination angle, Alsberg angle and the angle between the anatomical and mechanical axes of the femur in males. Surg Radial Anat. 1996; 18(1):29-31.

[10] Shrestha R , Gupta HK , Hamal RR , et al. Radiographic Anatomy of the neck-shaft angle of femur in Nepalese people: Correlation with its clinical implication. Kathmandu Univ Med J (KUMJ). 2018; 62(2):124-28.

[11]Tahir A, Hassan AW, Umar IM. A study of the collodiaphyseal angle of the femur in the North-Eastern Sub-Region of Nigeria. Niger J Med. 2001; 10(1):34-36.

[12]Laforgia R, Specchiulli F, Solarino G, et al. Radiographic variables in normal and osteoarthritic hips. Bull Hosp Jt Dis. 1996; 54(4):215-21.

[13]Mills HJ, Horne JG, Purdie GL. The relationship between proximal femoral anatomy and osteoarthrosis of the hip. Clin Orthop Relat Res. 1993; (288):205-8.

[14]Doherty M, Courtney P, Doherty S, et al. Nonspherical femoral head shape (pistol grip deformity), neck shaft angle, and risk of hip osteoarthritis: a case-control study. Arthritis Rheum. 2008; 58(10):3172-82.

[15] Reikerås O, Høiseth A. Femoral neck angles in osteoarthritis of the hip. Acta Orthop Scand. 1982; 53(5):781-84.

[16]Labronici PJ, de Oliveira Castro GN, Neto $\mathrm{SR}$, et al. Femoral anteversion and the neckshaft angle: relationship with hip osteoarthritis. Rev Bras Ortop. 2011; 46(1):69-74. 